\title{
Study on Connections Between Signature and Personality Using Eysenck Test: A Case Study of Iranian Signatures
}

\author{
Ashraf Karami \\ General Psychology, Islamic Azad University of Tabriz, Tabriz, Iran
}

Email address:

ashraf_karamii@yahoo.com

\section{To cite this article:}

Ashraf Karami. Study on Connections Between Signature and Personality Using Eysenck Test: A Case Study of Iranian Signatures. American Journal of Applied Psychology. Vol. 6, No. 1, 2017, pp. 6-14. doi: 10.11648/j.ajap.20170601.12

Received: January 11, 2017; Accepted: February 4, 2017; Published: March 10, 2017

\begin{abstract}
In this study the relationship between signature and personality characteristics is investigated. Various characteristics of signature such as size, style, change and favorite color and personality characteristics such as neuroticism (stability - instability) and Introversion and extraversion and integration of these dimensions and attributes associated with them are studied using Eysenck Personality Questionnaire to find the internal states of individuals. The sample used in this study consists of 68 people among the members of community (Miyaneh city in Iran, regardless of their job and position) randomly including 36 women and 32 men. In this study Chi-squared test and Eysenck Tests questionnaire is used in the form of 90 questions. The result of this study showed that extroverts have larger signature while introverts sign smaller. There is a relation between individuals' favorite colors and personality characteristics. No relation observed between individuals signatures (up to forth signature) and personality characteristics. According to results, extroverts sign embowed especially unstable extroverts. Introverts sign vertical and a line is observed around the signature. Complicated and horizontal signatures are more observed in unstable introverts and stable individuals respectively. Stable introverts often have annulated signatures.
\end{abstract}

Keywords: Signature, Signature Pressure, Signature Form, Personality Characteristics, Eysenck Test

\section{Introduction}

Behavior of live creatures is originated from a general construction called personality. Personality is a general concept that includes behavioral characteristics of individuals. Psychologist can consider some dimensions of individuals like introversion and extraversion and stability and instability by special psychological tests. These characteristics, affect people's behavior. Behaviors are the result of the interaction between genetic factors, past experiences, and labile environmental and social influences [4]. Personality assessment helps us to predict how people behave under various circumstances or how well a person might perform within certain roles [3]. Writing identification is called "graphology", technic or knowledge which determines personality and mental characteristics of individuals by study of handwritings. Handwritten signature is one of the oldest means of the human being to both authenticate him/herself and state that a certain document has been understood and accepted [13]. Identity verification based on authenticity assessment of a handwritten signature is an important issue in biometrics [5].

\section{Literature Review}

There are many methods which can be used for investigation of personality. In family drawing test, children draw their internal golden road which represents the happiness, sorrows, stresses, fears, anxiety and needs in their paintings [14]. One of the methods to realize the individuals' personality is handwriting and sample signatures analysis and personality can be guessed without people trying to hide their feelings and introduce themselves otherwise [1]. Some researchers studied the graphology research from 1975 before performing empirical research for ability evaluation to use graphology in psychology assessment and showed that obtained data from graphology in assessment could be very negative or useful. Graphology application in recruitment processes is a common method in many human resources companies. Papers published in this field often include methods which represent the feature of person's handwriting with required characteristics for any particular job in 
recruitment process. In some cases, a model design to measure particular types of personality in volunteers for a special job position; for example handwriting use for measuring active personality and management power of author. Handwriting features which provide a picture of individual are obtained through documentary indicators such as apparent structure of writing, size and form of letters, angles and slope of lines. After collecting, data classify using neutral network to predict right person to given job. An experimental structure with real samples uses to demonstrate the performance of this method. In recent years, group of psychologists concluded that comprehensive personality theories such as Freud, Jung and others have tried to answer all questions relating to human, but the answers have been unable, because of the human complexity and its multiple behavioral causes is more greater to fit in a theory, no matter how comprehensive, and can respond to all human problems. They believe that instead of paying attention to make comprehensive theories, it is better to lay theories that only focused, studied and analyzed one or two aspects of man's personality more completely [11].

\subsection{Eysenck Personality Factor}

British psychologist Hans Eysenck achieved two personality factor of introversion - extroversion and emotional stability - instability (in his own words neuroticism) with similar method of Raymond Cattell [7].

\subsection{Introversion - Extroversion}

According to Eysenck, extroverts and introverts tend to realistic and idealistic visions respectively. If they are conservative, introverts will tend to religious beliefs and attitudes, while extroverts will tend to vision of counting offenders penalty for death and whip and opposition to racial integration and humiliate the colored people [8].

\subsection{Neuroticism}

These people spend their time to do worthless behavior, especially behavior that has been internalized. A key element of neuroticism is inability to decision making. Most of psychologists believe that kind of hereditary preparation is necessary for neuroticism that pushes all of person's behavior to this preparation [10].

\subsection{Signature}

Signature structure is a phenomenon that starts in childhood. The first impression of children on paper is one point, and then draws concentric circles and scrawls. Signature symbolism began from date, while people put a sign under their posts and then signs became signature.

\subsection{Multiple Signatures}

People who are more relaxed have more obvious signatures. Write their name and draw a line under it. Mysterious people of the Middle East draw pattern and designs in signature. Complicated persons have more complex signature which don't recognize readily. Persons, who have simple character, sign simpler.

Signatures are the obvious name of people plus a mark (sign). This mark should be constant and has mystery to avoid abuse. Oval signatures with many lines through it and then being pulled down, often are symbol of chancellery, that is a great feeling of high-minded and ministerial secretaries, like king Nasereddin signature. Round signatures show that signer has a very simple and intimate personality. Square signatures are rare, in some cases referred to obsessions. Simple signature (name and family and a line) shows a simple and forthright character. These people have a different signature in official documents for cheque, but their typical sign is name and family that show their simplicity. Sometimes, very complicated signatures are for people who are distrustful and sometimes very simple signature are for people who have mental retardation. Signature should have a special mystery that no one can recognize it. Most of signatures are similar because four kinds of signatures are usual: Oval, round, confused signatures and signatures that have side or edge. For this reason, people recognition with their signatures is relatively valid [12]. Signature is a public image and handwriting represents the private image of people, both signature and handwriting is essential to analyze the characters personality [1].

It is not expected to realize all personality characteristics of individuals by his signature, because person behavior can have huge difference in home, society, workplace and etc. If signature and handwriting are similar, it can be concluded that the personality difference between private and community is low. But if this gap is wide, another personality should be considered for author and differences can be identified between his social behavior and inherent nature which is obvious from signature and handwriting respectively. These differences often appear in curved letters, for example, curved letters written in text, and bent back in signature or written vertically in text and embowed in signature. Sometimes these differences can be seen in the form of letters, for example the text written fast and hastily, while signature is ordered and separated or in a different way from the handwriting.

An illegible signature should not deceived you, especially if it is spread out, relax, very complicated, garbled and with camouflage. In this case, signer is escapee to disclose his name. Anyone may change his signature several times in the life. Often due to various reasons, signatures and handwriting don't change gradually and in parallel. Every fantasy action is free in children and teenagers, so signature changes have no basic concept. But when everybody is responsible for his circumstances and conditions and when his signature obliged him to respect the dignity, to defense the property or reputation and commit him to pay important documents, signature cannot change. For this reason, there are people who live all the lifetime with a mockery signature from youth period because they are involved with obligation and duties that 
start and continue with that mockery signature [2].

In this study the relationship between signature and personality characteristics is investigated. Various characteristics of signature such as size, style, change and favorite colors and personality characteristics such as neuroticism (stability - instability) and Introversion and extraversion and integration of these dimensions and attributes associated with them are studied using Eysenck Personality Questionnaire to find the internal states of individuals.

\section{Research Method}

\subsection{The Study Hypothesis}

Conjectures that can be raised about the relationship variables considered in this paper and the main hypothesis of this research can be considered as follows:

The size, pressure on paper to sign, changing the signature and favorite colors of the signature correlates positively with the personality trait extraversion.

\subsection{Operational Definition of Used Variables}

According to Eysenck's personality test, acquired individual score is compared with mean and standard deviation of Eysenck Personality Questionnaire based on their age for men and women and then the stability and instability, neuroticism is calculated and judged.

\subsubsection{Emotional Instability}

Achieving score above the average standard deviation based on Table 1, which indicates that the person absorb to the people who have emotionality, unstable and neuroticism trait and describe with words such as nervous, moody, irritable, restless, irritable, depressed, unreasonable, uncompromising, aggressive [9].

\subsubsection{Emotional Stability}

In front of the instability, creating strong, with words such as calm, carefree, lively, pioneer is known as moderate and stable. Achieving score to the average standard deviation based on Table 1 [9].

\subsubsection{Neuroticism}

(Factor $\mathrm{N}$ ); symbol of neuroticism is achieving score greater than $50 \%$ in scale $\mathrm{N}$ (neuroticism or emotional instability) (Table 1). Emotional imbalance, aggressive reaction, complaints of physical pain and anxiety are characteristics of these people. Score lower than $50 \%$ is sign of emotional stability, stability of behavior and emotional balance, relaxation and weaknesses of aggressive behavior [10].

\subsubsection{Discrete-Oriented Psychotherapy}

(Factor P); raw score above the average (see Table 1), indicates that a person tends to discrete-oriented psychotherapy. These are isolated individuals, apathy, impulsive, egocentric, aggressive, hardened, creative and oblivious to others [9].

\subsubsection{Introversion}

Score below the average including standard deviation (Table 1) in scale E, shows the introspective person. In this people, inactivity, withdrawal, depression and responsibilities is obvious [10].

\subsubsection{Extraversion}

(Factor E): score higher than the average including standard deviation in scale E (Table 1) shows the extraversion person, which is representative of activity, sociability, humor, optimism, and self-expression is risk acceptance and assertive [10].

\subsubsection{Desire for Social Acceptance}

(Factor L): L measures the sensitivity and tendency to socially acceptable. L higher than average including the standard deviation (Table 1), indicate the person who put himself in hardness to be accepted by others; this means that do anything just to be accepted by others! L is also considered as polygraph factor [9]. If $\mathrm{L}$ is too high (above 80 percent), it will not have good interpretation value [10].

\subsubsection{Signature}

Signature indicates general visual of our own. Image of ourselves which we wish to be and how we appear against others. Signature is our mark and unlike a handwritten is less influenced by our moment morality. Signature analysis includes the following:

I- Comparison of signature and handwriting size

- Signature very larger than handwriting: dramatic, unthinking, strong, looking for attention, pretentious.

- Signature slightly larger than handwriting: ambiguous, arrogant, self-sufficiency.

- Signature slightly smaller than handwriting: Insecure, introvert, cautious, shy.

- Signature very smaller than handwriting: Looking for attention, subordinate obsession, and lack of selfworth, humble, modesty.

- Signature equal to handwriting: same inside and outside, not hypocritical, and no different in appearance and reality.

II- Signature pressure

- High pressure: energetic, depletion of energy on paper can be a sign of happiness and anger.

- Low pressure: sensitive, low energy, lethargic, bashful

III- Signature style

- Angled signature: Aggressive (especially if angles and lines were sharp).

- Signature with zigzag line: Rigid, vindictive, and aggressive.

- Curved signature: Rounded and curved signature is sign of emotional, affectionate and kindness of author.

- Complicated signature: mental disruption, confidentiality, lack of honesty.

- Widespread signature: Occupies a large space in paper and shows the extroversion and self-esteem. 
- Rising signature: Perhaps jump, high-flying.

- Falling signature: Fatigue, psychological clearance, stubbornness.

- Horizontal signature: Fixed morality, cold temperament.

- Vertical and horizontal signature: If the signature width is greater than its length will indicate high selfesteem and awareness of one's own worth. Very high signature width is indicative of arrogance and egotism.

- Simple signature: Clear thinking, independent, balanced.

- Writing name and Family in signature: based on letters can be written by an educated or illiterate person [1].

$I V$ - Using segment in signature

- Line over signature: Defensive, selfish, insecure about your image with others. Half round line is sign of idealism.

- Line on writing signature: Selfish, self-satisfied immaturity, rogue, non-critical of themselves, unhappy, need to take care of themselves.

- Line around signature: Fear of disclosure, caution, confidentiality, and defensive, suspicious, secluded.
- Vertical line: Cautious and defensive.

- Using capital letter in signature: Self-satisfied, arrogant, the desire to become famous, need to be praised.

- Annulated: Politicians that change their direction with gentleness, softness and caution. Pen has rotational motion in return and changing direction. Their aggression is diplomatic.

- Signature line towards left and suddenly goes right steepness: Suppressive volition is strong which means that can stop the intensity of human emotions and desire and change their directions. Less trustworthy in friendship, pen thickness in return is symptom of more volition and violence.

\subsection{Statistical Sample}

The sample used in this study consists of 68 people among the members of community (Miyaneh city in Iran, regardless of their job and position) randomly including 36 women and 32 men.

Table 1. Mean and standard deviation of Eysenck Personality Questionnaire for Iranian women and men over 16 years old [9].

\begin{tabular}{|c|c|c|c|c|c|c|c|c|c|}
\hline & \multirow[t]{2}{*}{ Age } & \multicolumn{4}{|c|}{ Mean } & \multicolumn{4}{|c|}{ Standard Deviation } \\
\hline & & $\mathbf{P}$ & $\mathbf{E}$ & $\mathbf{N}$ & $\mathbf{L}$ & $\mathbf{P}$ & $\mathbf{E}$ & $\mathbf{N}$ & $\mathbf{L}$ \\
\hline \multirow{8}{*}{ Women } & 16 & 5.15 & 11.6 & 14.7 & 11.20 & 1.58 & 1.64 & 2.2 & 2.35 \\
\hline & 17 & 5.05 & 12.23 & 15.17 & 11.92 & 1.37 & 1.81 & 2.02 & 1.98 \\
\hline & 18 & 5.39 & 12.3 & 15.66 & 14.94 & 1.38 & 1.81 & 2 & 2.14 \\
\hline & 19 & 5.34 & 12.5 & 16.13 & 12 & 1.52 & 1.82 & 2.02 & 2.08 \\
\hline & $20-29$ & 5.04 & 9.89 & 14.99 & 12.97 & 1.35 & 1.8 & 2.35 & 1.98 \\
\hline & $30-39$ & 4.7 & 13.74 & 13.79 & 13.65 & 2.65 & 1.55 & 5.31 & 2.81 \\
\hline & $40-49$ & 4.88 & 12.05 & 13.85 & 13.85 & 2.71 & 3.37 & 4.5 & 3.65 \\
\hline & $50-59$ & 5.13 & 11.26 & 13.16 & 4.7 & 3.24 & 3.94 & 5.7 & 3.82 \\
\hline \multirow{8}{*}{ Men } & 16 & 6.55 & 13.49 & 13.71 & 11.76 & 1.75 & 1.64 & 2.03 & 2.04 \\
\hline & 17 & 6.43 & 12.95 & 12.98 & 11.7 & 1.5 & 1.66 & 2.31 & 2.9 \\
\hline & 18 & 6.02 & 12.26 & 13.41 & 12.28 & 2.78 & 1.6 & 2.3 & 2.18 \\
\hline & 19 & 6 & 12.21 & 13.6 & 11.7 & 1.48 & 1.27 & 2.38 & 1.95 \\
\hline & $20-29$ & 5.61 & 11.72 & 12.16 & 11.68 & 1.98 & 1.52 & 2.15 & 1.99 \\
\hline & $30-39$ & 7.7 & 11.94 & 11.7 & 12.02 & 2.13 & 1.43 & 1.78 & 1.87 \\
\hline & $40-49$ & 8.9 & 11 & 11.4 & 11.24 & 2.03 & 1.45 & 1.82 & 3.28 \\
\hline & $50-59$ & 5.3 & 10.11 & 12.51 & 10.5 & 1.77 & 0.4 & 1.79 & 1.58 \\
\hline
\end{tabular}

\subsection{Analysis Method}

Correlation between two variables has start from a range of -1 continues to +1 , this value called correlation coefficient. Correlation Coefficient calculates by the chi-square method as $\mathrm{C}$ adaptive coefficient. $\mathrm{C}$ is an indicator which calculates the correlation between two nominal variables setting up in a contingency table. Since determination of the variables relations is concerned, this study is correlational and chisquare test is applied. Variables in this paper were signature size, pen pressure in signing, changing signature, color and the score of individuals in the scales of Eysenck Personality Test. Signature of persons for each variable was measured with mentioned method, and then correlation calculated between signature and scales of Eysenck Personality Test.

Measuring Tools and Scoring Method

In this study Eysenck Tests questionnaire is used in the form of 90 questions.

Pay attention to the table of mean and standard deviation factors (Table 1) for interpretation of achieved scores. According to the scores for $\mathrm{N}$ and $\mathrm{E}$, one of the following modes for individual can be considered:

Instable extrovert: High $\mathrm{N}+$ High $\mathrm{E}$

Stable extrovert: Low N + High E

Stable introvert: Low $\mathrm{N}+$ High E

Instable introvert: High $\mathrm{N}+$ Low $\mathrm{E}$

If a person achieves high scores of $\mathrm{P}$ and low score of $\mathrm{E}$ and $\mathrm{N}$, in fact will be a healthy and creative person. Majority of neurotic patients achieve high score of $\mathrm{N}$ and low score of E. Against criminals and anti-social persons achieve high scores in all three factors of E, $\mathrm{P}$ and $\mathrm{N}$ [9]. High score $\mathrm{P}$ in educated persons, can show the opposition with the existing discipline. $\mathrm{P}$ and $\mathrm{E}$ in men are usually higher. 


\subsection{Determination of Questionnaire Reliability and Validity}

In order to determine the reliability and validity of the questionnaire, Eysenck it performed on a single group at two different times and obtained its validity and reliability. Internal validity coefficient for men was, $\mathrm{P}=0.78, \mathrm{E}=0.90$, $\mathrm{N}=0.88, \mathrm{~L}=0.82$ and for women $\mathrm{P}=76, \mathrm{~N}=0.85, \mathrm{~L}=0.79$. In the Iranian sample reliability coefficient with retest method and interval of two months is reported as follows: $\mathrm{P}=0.92$, $\mathrm{N}=0.88, \mathrm{~N}=0.89, \mathrm{P}=0.72$, which indicates very high reliability and acceptability [9].

\subsection{Statistical Method}

In this study, all required descriptive and inferential statistics methods are applied. Charts were used to present the results. Several variables were investigated: Person's handwriting (variables was mentioned previously) and person's score in the scales of E, N, P Eysenck Personality test to examine their relationship by chi-square test. Applied formula is as follow:

$$
\chi^{2}=\sum \frac{(O-E)^{2}}{E}
$$

$\chi^{2}=$ Chi-square

$\mathrm{O}=$ Observed or measured frequency

$E=$ Expected or assumptive frequency

According to the research hypotheses, the following formula for the correlation calculation is used ( $c$ is number of subjects):

$$
C=\sqrt{\frac{\chi^{2}}{\chi^{2}+n}}
$$

\section{Results and Discussion}

\subsection{Descriptive Statistical Analysis}

Descriptive methods usually use to determine and express the characteristics or information collected by the researchers. Individual scores in Eysenck Personality factors and signatures with its measuring method are presented which is tested on 68 people. In the following frequency and percentage of subjects responds to studied variables are presented and chart of each variable is compared with variable classes in each Eysenck Personality factors.

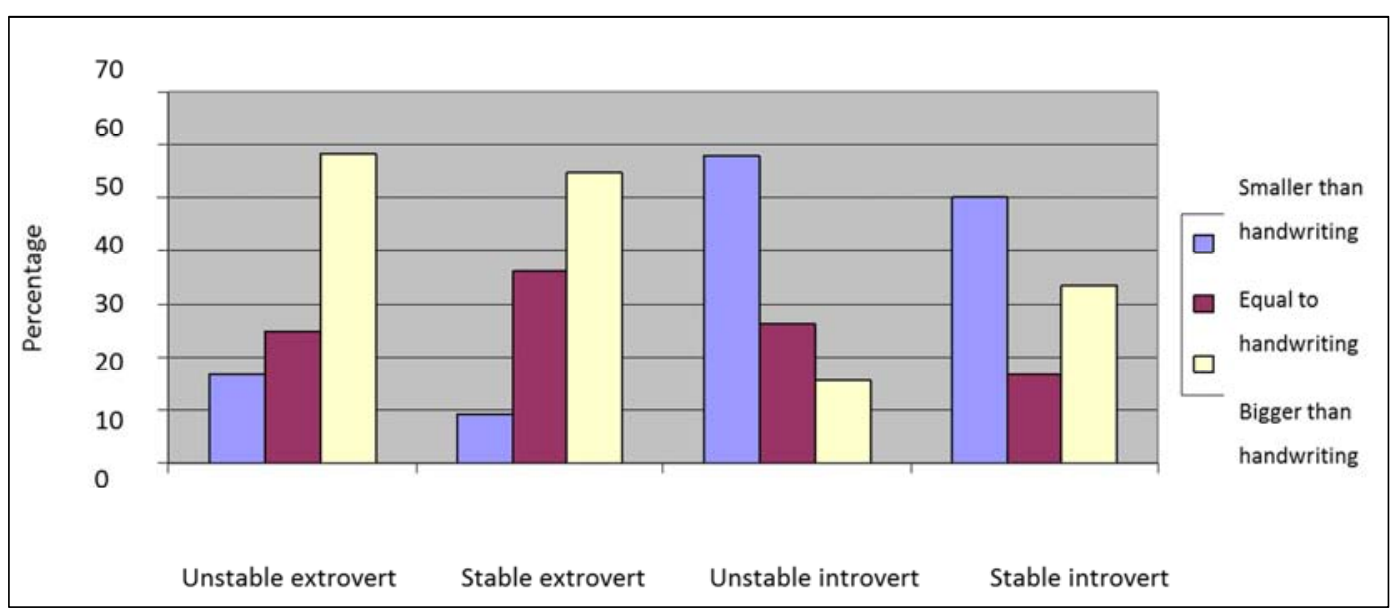

Figure 1. Percentage of subjects responds to signature size variable by Eysenck Personality factors.

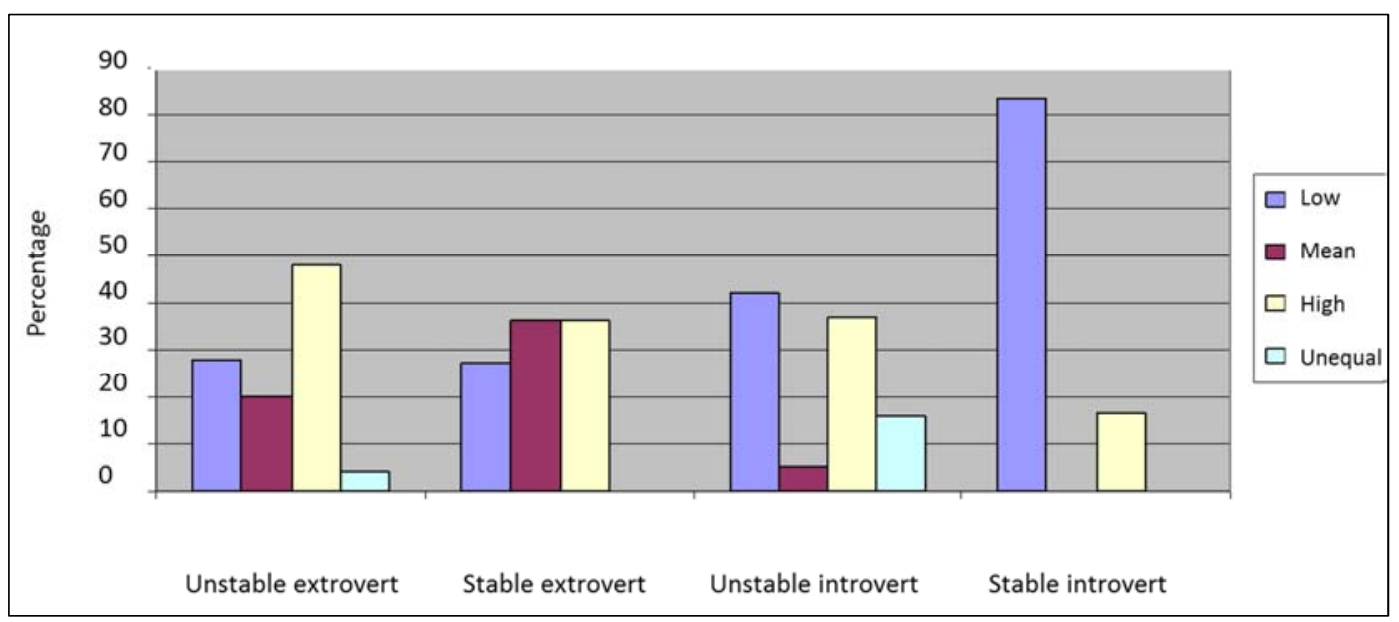

Figure 2. Percentage of subjects responds to signature pressure variable. 


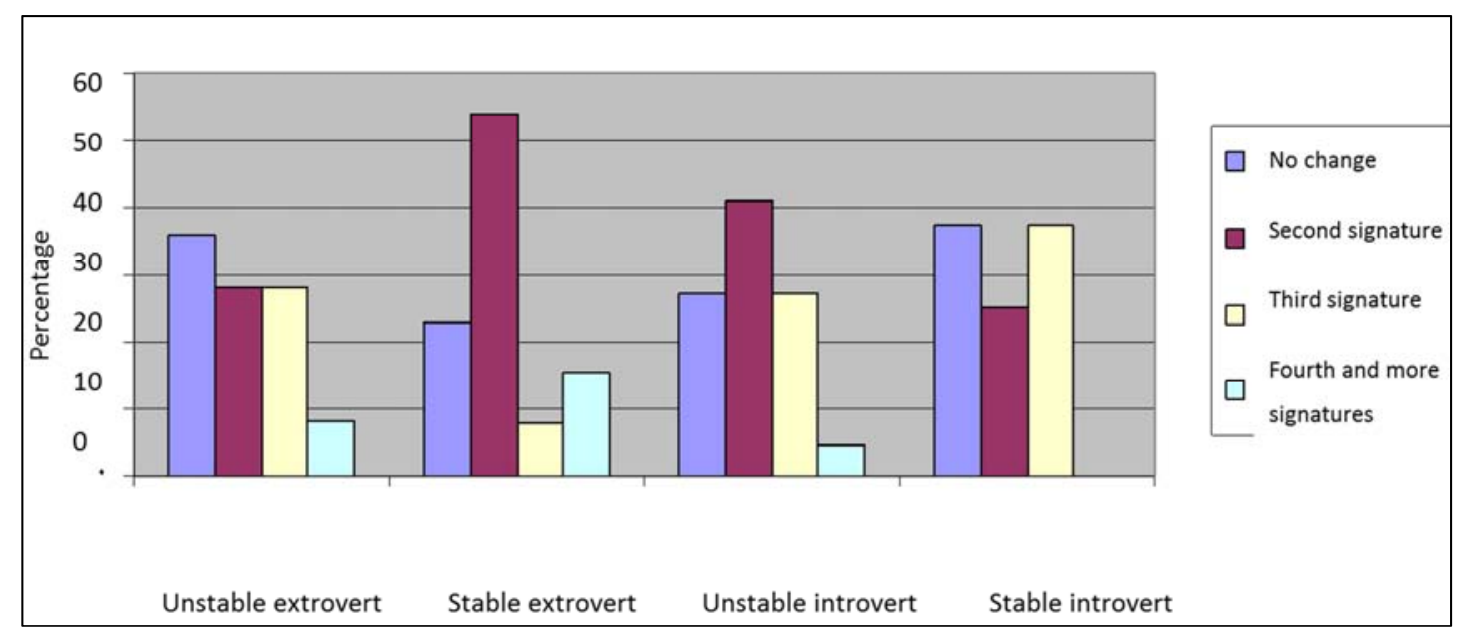

Figure 3. Percentage of subjects responds to changing signature variable.

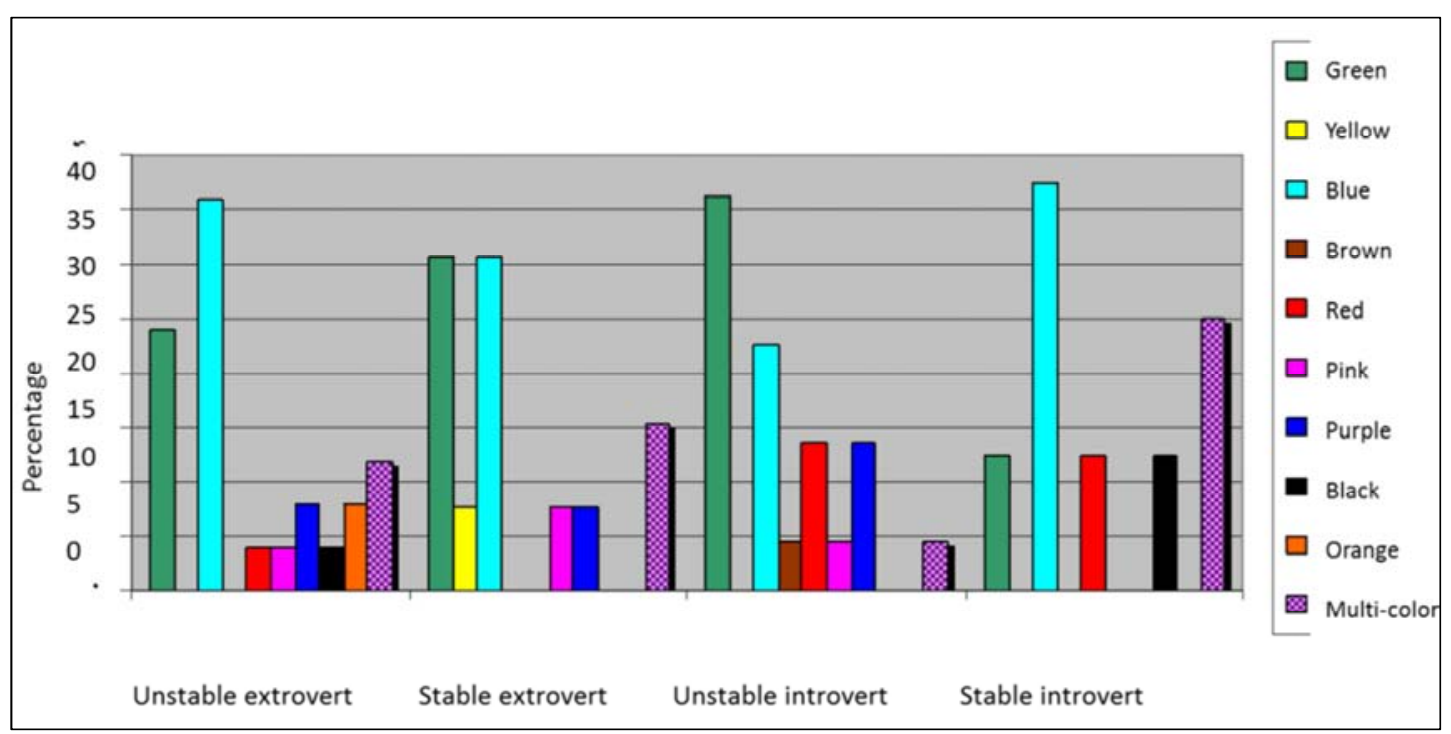

Figure 4. Percentage of subjects responds to color variable.

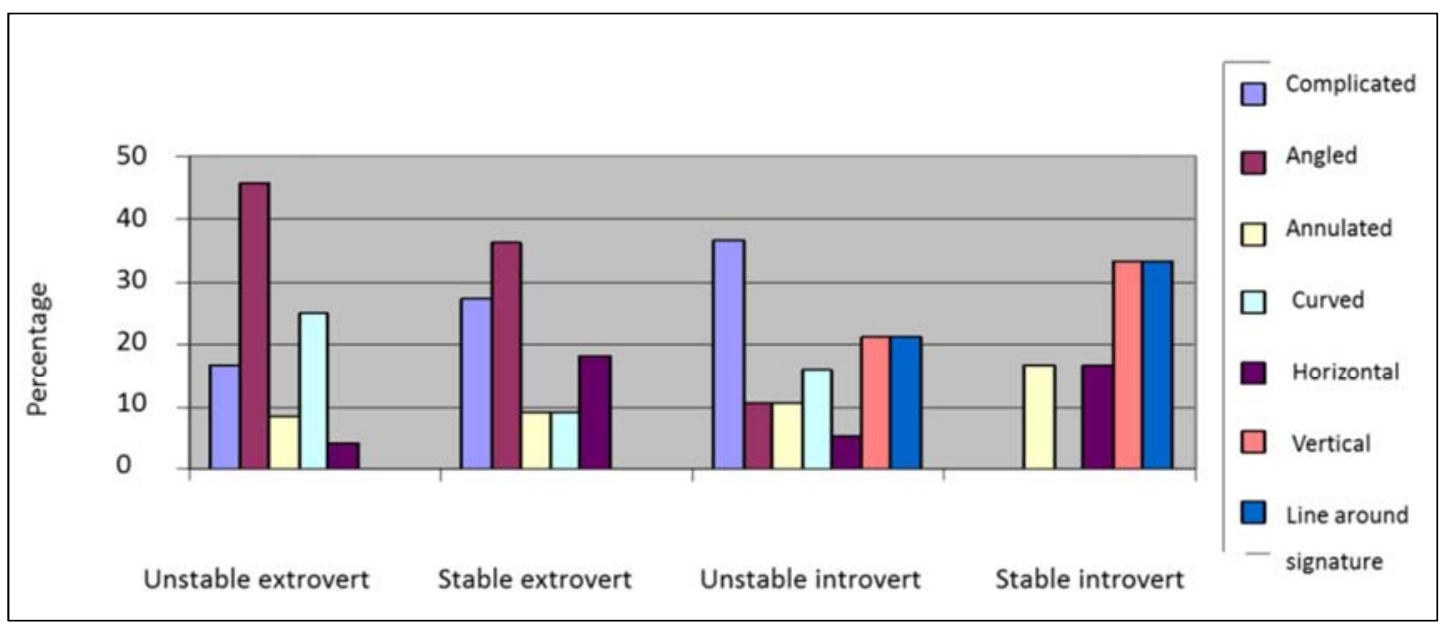

Figure 5. Percentage of subjects responds to signature style variable. 


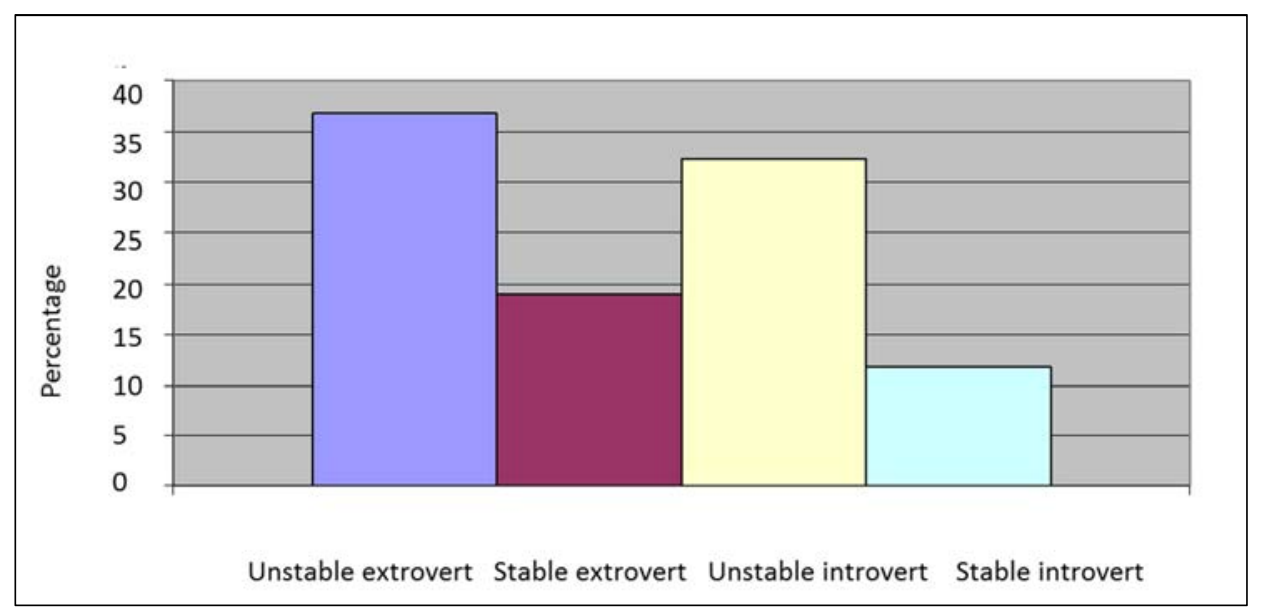

Figure 6. Percentage of classified people in quadratic personality based on Eysenck questionnaire.

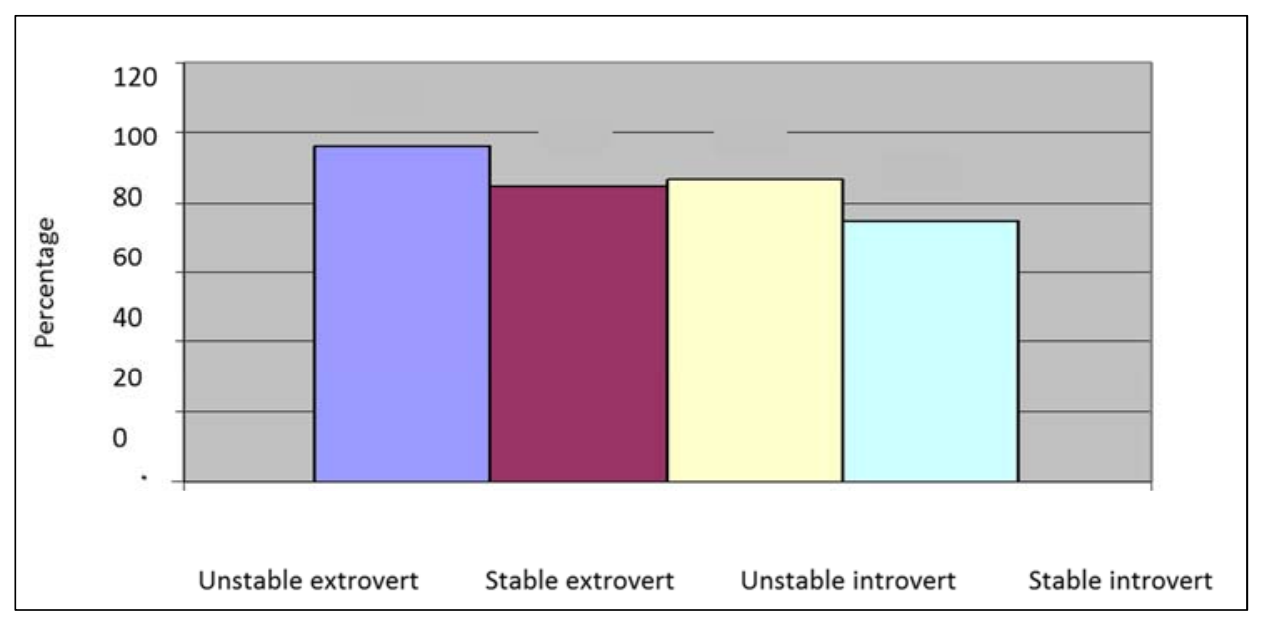

Figure 7. Percentage of subjects responds to signature demand at the end of handwriting.

\subsection{Inferential Analysis}

The tables for calculation of variables test and correlation are listed in next page separately. Table G (Chi-square distribution) is used to investigate the significant levels [6].
Note: 8 person didn't sign their papers so $\mathrm{n}$ is different in table of Chi-square calculation for variable related to signatures.

Table 2. Chi-square for signature size (compared to handwriting size) variable.

\begin{tabular}{|c|c|c|c|c|c|c|c|c|c|c|c|c|c|c|c|c|c|c|}
\hline \multirow[b]{2}{*}{ Classes } & \multicolumn{3}{|c|}{ Unstable extrovert } & \multicolumn{5}{|c|}{ Stable extrovert } & \multicolumn{3}{|c|}{ Unstable introvert } & \multicolumn{4}{|c|}{ Stable introvert } & \multicolumn{3}{|c|}{ Total } \\
\hline & $\mathbf{O}$ & $\mathbf{E}$ & $O-E$ & $\frac{(\boldsymbol{O}-E)^{2}}{E}$ & $\mathbf{O}$ & $\mathbf{E}$ & $O-E$ & $\frac{(\boldsymbol{O}-E)^{2}}{E}$ & $\mathbf{O}$ & $\mathbf{E}$ & $\boldsymbol{O}-\boldsymbol{E}$ & $\frac{(\boldsymbol{O}-E)^{2}}{E}$ & $\mathbf{O}$ & $\mathbf{E}$ & $O-E$ & $\frac{(\boldsymbol{O}-E)^{2}}{E}$ & $\mathbf{O}$ & $\mathbf{E}$ \\
\hline Smaller & 4 & 7.6 & -3.6 & 1.7 & 1 & 3.5 & -2.5 & 1.8 & 11 & 6 & 5 & 4.16 & 3 & 1.9 & 1.1 & 0.636 & 19 & 19 \\
\hline Equal & 6 & 6.4 & -0.4 & 0.025 & 4 & 2.9 & 1.1 & 0.42 & 5 & 5.1 & 0.1 & 0.002 & 1 & 1.6 & 0.6 & 0.225 & 16 & 16 \\
\hline Bigger & 14 & 10 & 4 & 1.6 & 6 & 4.6 & 1.4 & 0.426 & 3 & 7.9 & -4.9 & 3.04 & 2 & 2.5 & 0.5 & 0.1 & 25 & 25 \\
\hline Sum & 24 & 24 & 3.325 & 11 & 11 & & 2.646 & 19 & 19 & & 7.202 & 6 & 6 & 6 & & 0.961 & 60 & 60 \\
\hline
\end{tabular}

Correlation coefficient

$$
\begin{gathered}
C=\sqrt{\frac{\chi^{2}}{\chi^{2}+n}}=\sqrt{\frac{14.13}{14.13+60}}=\sqrt{0.19}=0.43 \\
\chi^{2}=\sum \frac{(O-E)^{2}}{E}=14.13
\end{gathered}
$$

Domain of Freedom $(\mathrm{df})=($ number of rows- 1$)($ number of column-1)

$$
d f=(3-1)(4-1)=2 \times 3=6
$$

Based on Table $\mathrm{G} \propto=0.05 \rightarrow \chi^{2}=12.59$

Calculated Chi-square is greater than table Chi-square, so research hypothesis is accepted with $95 \%$ confidence level. According to Table 2 extroverts have bigger signatures, while introverts sign smaller. 
Table 3. Chi-square for signature pressure variable.

\begin{tabular}{|c|c|c|c|c|c|c|c|c|c|c|c|c|c|c|c|c|c|c|}
\hline \multirow[b]{2}{*}{ Classes } & \multicolumn{3}{|c|}{ Unstable extrovert } & \multicolumn{4}{|c|}{ Stable extrovert } & & \multicolumn{3}{|c|}{ Unstable introvert } & \multicolumn{4}{|c|}{ Stable introvert } & \multicolumn{3}{|c|}{ Total } \\
\hline & $\mathbf{O}$ & $\mathbf{E}$ & $O-E$ & $\frac{(\boldsymbol{O}-E)^{2}}{E}$ & $\mathbf{O}$ & $\mathbf{E}$ & $\boldsymbol{O}-\boldsymbol{E}$ & $\frac{(O-E)^{2}}{E}$ & $\mathbf{O}$ & $\mathbf{E}$ & $O-E$ & $\frac{(\boldsymbol{O}-E)}{E}$ & 0 & $\mathbf{E}$ & $O-E$ & $\frac{(O-E)^{2}}{E}$ & $\mathbf{O}$ & $\mathbf{E}$ \\
\hline Low & 7 & 9.2 & -2.2 & 0.526 & 3 & 4.21 & -1.21 & 0.347 & 8 & 7.28 & 0.72 & 0.071 & 5 & 2.3 & 2.7 & 3.169 & 23 & 23 \\
\hline Mean & 5 & 4 & 1 & 0.25 & 4 & 1.83 & 2.17 & 2.57 & 1 & 3.16 & -2.16 & 1.476 & 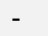 & 1 & -1 & 1 & 10 & 10 \\
\hline High & 12 & 9.6 & 2.4 & 0.6 & 4 & 4.4 & 0.4 & 0.036 & 7 & 7.6 & -0.6 & 0.047 & 1 & 2.4 & -1.4 & 0.816 & 24 & 24 \\
\hline Unequal & 1 & 1.6 & 0.6 & 0.225 & - & 0.73 & -0.73 & 0.73 & 3 & 1.26 & 1.74 & 2.4 & - & 0.4 & -0.4 & 0.4 & 4 & 4 \\
\hline Sum & 24 & 24 & & 1.6 & 11 & 11 & & 3.67 & 19 & 19 & & 3.994 & 6 & 6 & & 5.385 & 60 & 60 \\
\hline
\end{tabular}

Chi-square in signature pressure is 14.67. Table Chi-square considering degree of freedom 9 is 16.92 . Calculated Chi-

square is greater than table Chi-square, so research hypothesis is accepted with $95 \%$ confidence level.

Table 4. Chi-square for color variable.

\begin{tabular}{|c|c|c|c|c|c|c|c|c|c|c|c|c|c|c|c|c|c|c|}
\hline & \multicolumn{3}{|c|}{ Unstable extrovert } & \multicolumn{4}{|c|}{ Stable extrovert } & \multicolumn{4}{|c|}{ Unstable introvert } & \multicolumn{4}{|c|}{ Stable introvert } & \multicolumn{3}{|c|}{ Total } \\
\hline $\begin{array}{l}\text { Color } \\
\text { Classes } \\
\end{array}$ & $\mathbf{O}$ & $\mathbf{E}$ & $\boldsymbol{O}-\boldsymbol{E}$ & $\frac{(\boldsymbol{O}-E)^{2}}{E}$ & $\mathbf{O}$ & $\mathbf{E}$ & $\boldsymbol{O}-\boldsymbol{E}$ & $\frac{(\boldsymbol{O}-E)^{2}}{E}$ & $\mathbf{O}$ & $\mathbf{E}$ & $\begin{array}{l}\boldsymbol{O} \\
-E \\
\end{array}$ & $\frac{(\boldsymbol{O}-\boldsymbol{E})^{2}}{E}$ & $\mathbf{O}$ & $\mathbf{E}$ & $O-E$ & $\frac{(\boldsymbol{O}-E)^{2}}{E}$ & $\mathbf{O}$ & $\mathbf{E}$ \\
\hline Green & 6 & 7 & -1 & 0.14 & 4 & 6.63 & 0.37 & 0.04 & 8 & 6.15 & 1.85 & 0.55 & 1 & 2.23 & -1.23 & 0.67 & 19 & 19 \\
\hline Blue & 9 & 7.7 & 1.28 & 0.21 & 4 & 4 & 0 & 0 & 5 & 6.8 & -1.8 & 0.47 & 3 & 2.48 & 0.52 & 0.1 & 21 & 21 \\
\hline Brown & - & 0.4 & -0.4 & 0.4 & - & 0.2 & -0.2 & 0.2 & 1 & 0.3 & 0.7 & 1.63 & - & 0.1 & -0.1 & 0.1 & 1 & 1 \\
\hline Red & 1 & 1.8 & 0.83 & 0.37 & - & 0.95 & -0.95 & 0.95 & 3 & 1.61 & 1.39 & 1.2 & 1 & 0.6 & 0.4 & 0.26 & 5 & 5 \\
\hline Pink & 1 & 1.1 & -0.1 & 0.009 & 1 & 0.6 & 0.4 & 0.26 & 1 & 0.97 & 0.03 & 0.001 & - & 0.33 & -0.33 & 0.33 & 3 & 3 \\
\hline Purple & 2 & 2.2 & -0.2 & 0.018 & 1 & 1.1 & -0.1 & 0.009 & 3 & 2 & 1 & 0.5 & - & 0.7 & -0.7 & 0.7 & 6 & 6 \\
\hline Black & 1 & 0.73 & 0.27 & 0.01 & - & 0.4 & -0.4 & 0.4 & - & 0.65 & -0.65 & 0.65 & 1 & 0.23 & 0.77 & 2.57 & 2 & 2 \\
\hline Orange & 2 & 0.73 & 0.27 & 0.01 & - & 0.4 & -0.4 & 0.4 & - & 0.62 & -0.62 & 0.62 & - & 0.24 & -0.24 & 0.24 & 2 & 2 \\
\hline $\begin{array}{l}\text { Multi- } \\
\text { color }\end{array}$ & 3 & 2.9 & 0.1 & 0.003 & 2 & 1.52 & 0.48 & 0.15 & 1 & 2.6 & -1.6 & 0.98 & 2 & 0.98 & 1.02 & 1.06 & 8 & 8 \\
\hline Total & 25 & 25 & & 1.57 & 13 & 13 & & 5.6 & 22 & 22 & & 6.9 & 8 & 8 & & 6.14 & 68 & 68 \\
\hline
\end{tabular}

Chi-square in color variable is 20.21. Table Chi-square considering degree of freedom 27 is 40.11. Calculated Chisquare is greater than table Chi-square, so research hypothesis is accepted with $95 \%$ confidence level.

There is a relation between individuals' favorite colors and personality characteristics. This is not related to handwriting and signature, but since is an interesting subject, a question inserted in questionnaire which asks individuals to determine favorite color. This was for investigation of whether favorite color is affected by special personality character or not?

Maybe results become dubious according to individuals' distribution in different classes (10 classes) and spreading individuals (in Chi-square calculation, number of individuals should not be less than 5 when number of rows are large) and small number of sample to number of rows.

Since according to Figure 4 and Table of frequency and variable percentages, it can be understood that;

In summing up the participants into two groups of introversion and extroversion: 1. Extroverts are more interested in blue and introverts in green. 2. The amount of color variation is more in extraversions; it means that they prefer more colors.

In summing up the participants into two groups of stable and unstable (factor $\mathrm{N}$ ); the individuals' distribution in different classes in unstable persons is more while the distribution is done in limited classes in stable persons. However, in this area more research is required.

Table 5. Chi-square for changing signature variable.

\begin{tabular}{|c|c|c|c|c|c|c|c|c|c|c|c|c|c|c|c|c|c|c|}
\hline & \multicolumn{4}{|c|}{ Unstable extrovert } & \multicolumn{3}{|c|}{ Stable extrovert } & \multicolumn{5}{|c|}{ Unstable introvert } & \multicolumn{3}{|c|}{ Stable introvert } & \multicolumn{3}{|c|}{ total } \\
\hline $\begin{array}{l}\text { Changing } \\
\text { Classes }\end{array}$ & $\mathbf{O}$ & $\mathbf{E}$ & $\boldsymbol{O}-\boldsymbol{E}$ & $\frac{(\boldsymbol{O}-E)^{2}}{E}$ & $\mathbf{O}$ & $\mathbf{E}$ & $\begin{array}{l}\boldsymbol{O} \\
-E\end{array}$ & $\frac{(\boldsymbol{O}-E)^{2}}{E}$ & $\mathbf{O}$ & $\mathbf{E}$ & $\begin{array}{l}\boldsymbol{O} \\
-E\end{array}$ & $\frac{(\boldsymbol{O}-E)^{2}}{E}$ & $\mathbf{O}$ & $\mathbf{E}$ & $O-E$ & $\frac{(\boldsymbol{O}-E)^{2}}{E}$ & $\mathbf{O}$ & $\mathbf{E}$ \\
\hline No change & 9 & 7.72 & 1.28 & 0.21 & 3 & 4.01 & 1.01 & 0.25 & 6 & 6.79 & -0.79 & 0.1 & 3 & 2.48 & 0.52 & 0.11 & 21 & 21 \\
\hline Second & 7 & 9.2 & -2.2 & 0.52 & 7 & 4.78 & 2.22 & 1.03 & 9 & 8.1 & 0.9 & 0.1 & 2 & 2.92 & 0.92 & 0.29 & 25 & 25 \\
\hline Third & 7 & 6.25 & 0.75 & 0.09 & 1 & 3.25 & -2.25 & 1.55 & 6 & 5.5 & 0.5 & 0.45 & 3 & 2 & 1 & 0.5 & 17 & 17 \\
\hline $\begin{array}{l}\text { fourth and } \\
\text { more }\end{array}$ & 2 & 1.83 & 0.17 & 0.005 & 2 & 0.95 & $1-.05$ & 1.16 & 1 & 1.61 & -0.61 & 0.231 & - & 0.6 & 0.6 & 0.6 & 5 & 5 \\
\hline Total & 25 & 25 & & 0.835 & 13 & 13 & & 3.99 & 22 & 22 & & 0.881 & 8 & 8 & & 1.5 & 68 & 68 \\
\hline
\end{tabular}

Chi-square in changing signature variable is 7.20. Table Chi-square considering degree of freedom 9 is 16.92 . Calculated Chi-square is smaller than table Chi-square, so research hypothesis is rejected with $95 \%$ confidence level. It means that no relation observed between individuals signatures (up to forth signature) and personality characteristics.

According to many classes in this variable and possibility of spreading individuals in classes and probability of ambiguous results, some of classes integrated (one of chisquare calculation condition). Number of individuals due to using combination classes has possibility to be in multi classes. Here according to obvious feature of each signature, individuals are in respective classes. Calculated score of $\chi^{2}$ is 30.99 and table $\chi^{2}$ in $\mathrm{G}$ distribution and in 0.05 confidence level is 28.87. Calculated $\chi^{2}$ is greater than table $\chi^{2}$, so 
research hypothesis is accepted with $95 \%$ confidence level and correlation coefficient is 0.58 .

According to Figure 5 (signature style frequency), it can be seen angled signature in extroverts persons particularly unstable extroverts which is explicitly less in introverts. Introverts have vertical signatures and a line around signature. Complex signatures referred to stable introverted people and horizontal signatures can be seen in stable people. Also introverts signatures are more annulated.

\section{Conclusion}

Correlation between two or more variable don't represent casual relation between them; variable as operative of other variables cannot be realized from the correlation between two variables. However correlation shows that there is relation between two variable and obtained scores show the relation between noted variables in terms of individuals' personality and signatures. According to the results, extroverts have greater signatures, while the introverts sign smaller.

In summing up the participants into two groups of introversion and extroversion: 1. Extroverts are more interested in blue and introverts in green. 2. The amount of color variation is more in extraversions; it means that they prefer more colors.

According to results, extroverts sign embowed especially unstable extroverts. Introverts sign vertical and a line is observed around the signature. Complicated and horizontal signatures are more observed in unstable introverts and stable individuals respectively. Stable introverts often have annulated signatures.

\section{References}

[1] Aghayousefi, A. R. 2009. Personality analysis based on handwriting. Lamak publication, Qom.
[2] Beauchataud, G. 1997. Translated by Yalda, A. geography and personality, Ketabsara Publication, Tehran.

[3] Boag, Simon (2015). Personality assessment, 'construct validity', and the significance of theory. Personality and Individual Differences, 84: 36-44.

[4] Bousqueta, Christophe A. H., Odile Petita, Mathilde Arrivéa, Jean-Patrice Robina, Cédric Sueur (2015). Personality tests predict responses to a spatial-learning task in mallards, Anas platyrhynchos, Animal Behaviour, 110: 145-154.

[5] Cpałka, Krzysztof, Marcin Zalasiński, and Leszek Rutkowski (2016). A new algorithm for identity verification based on the analysis of a handwritten dynamic signature. Applied Soft Computing, 43: 47-56.

[6] Delavar, A. 2008. Applied Statistic and Probability in psychology and educative sciences. Roshd Publication, Tehran.

[7] Eysenck, H. J. (1953). The structure of human personality. Wiley, New York.

[8] Eysenck, H. J. (1999). Reality and fantasy in Psychology, Translated to Persian by Mohammad Naghi Barahani, Roshd Publication, Tehran.

[9] Fathi Ashtiani, S. 2009. Psychological tests. Be'sat Publication, Tehran.

[10] Ganji, H. 2007. Personality evaluation. Savalan Publication, Tehran.

[11] Karimi, Yusef, (1991). Personality Psychology, Payame Nour University, Tehran.

[12] Majd, M. 2009. Face, handwriting and signature psychology, speech, Pezhvak honar va andishe publication.

[13] Sanchez-Reillo, Raul (2016). Signature analysis in the context of mobile devices. Image and Vision Computing, doi:10.1016/j.imavis.2016.03.011. (In Press).

[14] Trakhan, M. 2007. Personality evaluation, Payame Nour University. 